\title{
TO THE STARS
}

Trade mission.

\section{BY KEN LIU AND SHELLY LI}

\section{Ad Astra Community Forum}

twinkle_twinkle (moderator): Last week, ISS scientists announced that they've confirmed spectral signatures of water, methane, ozone and carbon dioxide in the atmosphere of the fourth planet orbiting Gliese 581. Hopefully, intelligent beings occupy this planet. As ISS scientists have not detected any electromagnetic radiation, we can assume that Gliese 581 is not any more technologically advanced than Earth. The natural next step is to establish contact. Marco Polo forged his way down the Silk Road in the late thirteenth century, fostering trade between Europe and Asia. Likewise, Ad Astra prides itself on its pioneering investment in space exploration. We have decided to fund a private trade mission to Gliese 581, to be launched next year. Ad Astra predicts much potential for interstellar trade in the years to come. Estimated flight time is 40 years, so the maximum payload we can transport is 200 kilograms and nonperishable (though if anyone knows of a way to get cheap antimatter so we can boost the payload, feel free to mention in the comments). Mostly importantly, Ad Astra is seeking your suggestions. What should we carry to Gliese 581? As long as it fits the requirements listed above, we will be happy to hear your thoughts. If we use your suggestion, you may receive an honorarium of one-tenth of $1 \%$ from our profits. (Note: the right to receive the honorarium is not assignable or transferable by inheritance.)

nolo_contendere (forum astronaut, second class): A non-assignable royalty of $0.1 \%$ ? Are you kidding? As it'll be at least 80 years before your ship even gets back, only kids will take up your offer. Good luck shipping pokemons and cotton candy to methane breathers.

iheartlucy (forum space cadet): Haven't they been awash in signals from our reruns for decades with nothing to watch them on? Can we ship them TV sets and charge for every show, INCLUDING COMMERCIALS? It'll be the ultimate syndication market.

Anon_4437 (forum guest): Is everyone asleep here? The first priority ought be to conquer them. If they haven't got to radio yet, we should send a platoon of Marines and take them down like Pizarro did in Peru. Then we can take whatever we want.

iamnotneilarmstrong (forum astronaut, second class): 4437 , check your reading

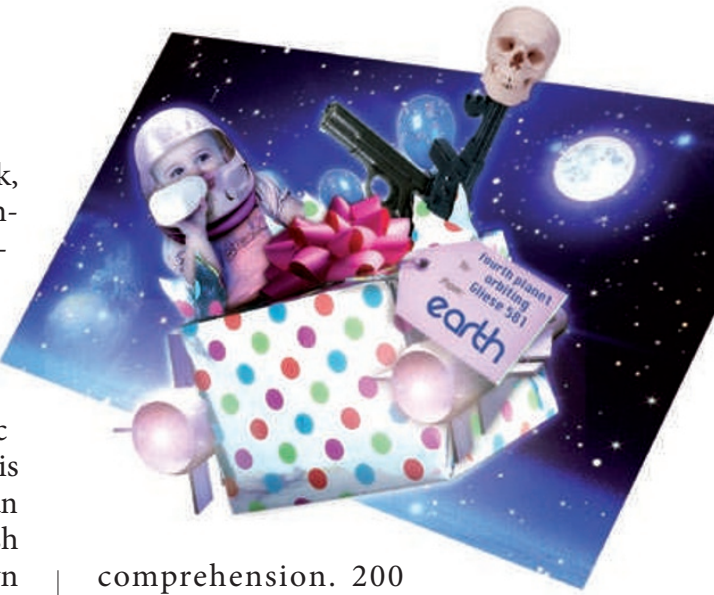

kilos is the limit. And NON-

PERISHABLE.

Anon_4437: Oh, right. How about one fully equipped attack drone then?

twinkle_twinkle: 4437, grow up. This is a trading mission of peace.

Anon_4437: You don't get to the top of the food pyramid by being politically correct wimps. I'm giving you the most economically efficient suggestion.

twinkle_twinkle: I've banned 4437's IP. Please keep the discussion focused.

iheartlucy: Does anybody know how to delete a previous post? I have a friend who might get me a meeting with some TV execs, and I wanna keep my idea for them. I copyright it. I patent it. Don't take it.

iamnotneilarmstrong: No one cares. How do you know if the aliens even have eyes? Or a sense of humour?

triune (forum astronaut, first class): What about just trading for ideas? With the cost of fuel, it's uneconomical to trade even for diamonds. Probably best to use the weight allotment for a powerful transmitter, then we can just phone back and forth and share discoveries.

iamnotneilarmstrong: Long time no see, triune! Where've you been? I like your idea, not the least because it cuts down travel time to light speed, so only 40 years round-trip. What are the first ideas we want to share with them?

triune: Democracy, pacifism and a dose of the greatest hits from our religions.

veryliberal (forum guest): triune, how is this better than Anon_4437's very sensible suggestion? You want to brainwash $\rightarrow$ NATURE.COM

Follow Futures on Facebook at: go.nature.com/mtoodm them with opiates for the masses and then take their stuff? At least Anon_4437 was honest. twinkle_twinkle: I’ve banned veryliberal. The account seems 㫕 to be a sock puppet for 4437 . musings033 (forum guest): I agree with triune's assessment on the economics of physical goods (also keep in mind that there is actually an infinitesimal chance of possessing something that another form of intelligence would want). As for specific ideas to transmit, why not just try to get to know each other first? The best way to do that, I think, is to be open and honest about our world, in hopes of reciprocation. We can compile a narrative - a BBC 'documentary' if you will — on Earth, our lands and oceans and all our beautiful organisms and ideas and constructions, culminating with the growth and maturation of a baby. Meanwhile, we'll also send a documentary that details our killing fields and memorials, our faces of fear and courage, our acts of barbarism and compassion upon one another and upon our planet. I don't know how we'll show them everything, but if the beings cannot see, we will make them hear. If they cannot hear, we will make them feel. We are good and beautiful, and we have given Earth scars that will never properly heal. And so we will present to Gliese 581 our humanity, the purest and the evilest thing in our possession. That, in itself, is the first idea worth trading.

twinkle_twinkle: That's a very complicated 'first idea'.

triune: I fully support a gift to Gliese 581 . The only thing I'd warn against is miscommunication. Should we even make it seem as if we expect anything in return?

thisisfutile888 (forum guest): Okay, musings, I think you've logged into the wrong forum. Space Cakes Conversations is another Google button away. Seriously, 'documentaries' about a human baby and another centred around humanity's thirst for blood and conquest? The first idea makes me want to vomit, and the second will get us all killed. Why not load up Free Willy and The Little Mermaid and force a couple of death-row prisoners to care for them? Gliese 581 will piss delight.

twinkle_twinkle: I've banned thisisfutile888. The future is just lost on some people.

Ken Liu is a lawyer and programmer. You can read more of his fiction at http://kenliu.name/ stories. Shelly Li does not believe in working, although her first novel, The Royal Hunter, is forthcoming from Penguin Books in 2011. To learn more, visit www.shelly-li.com. 